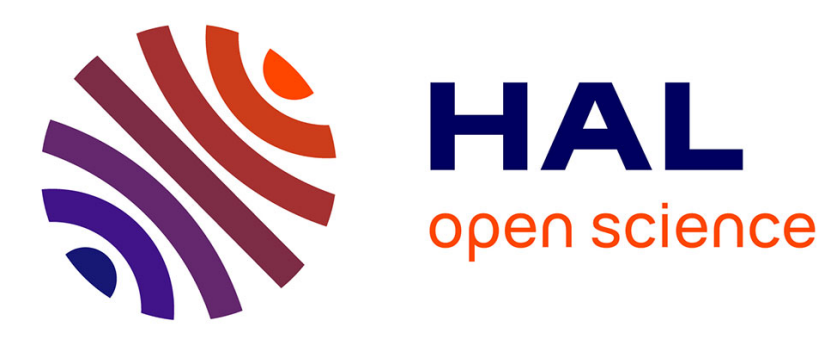

\title{
The influence of temperature on the charging of polytetrafluoroethylene surfaces in electrolyte solutions
}

Antun Barišić, Johannes Lützenkirchen, Grégory Lefèvre, Tajana Begović

\section{To cite this version:}

Antun Barišić, Johannes Lützenkirchen, Grégory Lefèvre, Tajana Begović. The influence of temperature on the charging of polytetrafluoroethylene surfaces in electrolyte solutions. Colloids and Surfaces A: Physicochemical and Engineering Aspects, 2019, 579, pp.123616. 10.1016/j.colsurfa.2019.123616 . hal-02382211

\section{HAL Id: hal-02382211 \\ https://hal.science/hal-02382211}

Submitted on 27 Nov 2019

HAL is a multi-disciplinary open access archive for the deposit and dissemination of scientific research documents, whether they are published or not. The documents may come from teaching and research institutions in France or abroad, or from public or private research centers.
L'archive ouverte pluridisciplinaire HAL, est destinée au dépôt et à la diffusion de documents scientifiques de niveau recherche, publiés ou non, émanant des établissements d'enseignement et de recherche français ou étrangers, des laboratoires publics ou privés. 


\title{
The influence of temperature on the charging of Polytetrafluoroethylene surfaces in electrolyte solutions
}

\author{
Antun Barišića , Johannes Lützenkirchen ${ }^{\mathrm{b}}$, Grégory Lefévre ${ }^{\mathrm{c}}$, Tajana Begovića ${ }^{\mathrm{a} *}$,
}

${ }^{a}$ Department of Chemistry, Faculty of Science, University of Zagreb, Horvatovac 102A, HR10000 Zagreb, Croatia

${ }^{b}$ Institut für Nukleare Entsorgung, Karlsruher Institut für Technologie, P.O. Box 3640, 76021 Karlsruhe, Germany

${ }^{c}$ PSL Research University, Chimie ParisTech - CNRS, Institut de Recherche de Chimie Paris, 75005, Paris, France

*Corresponding author: Tajana Begović, e-mail: tajana@chem.pmf.hr

Johannes Lützenkirchen, Antun Barišić, Grégory Lefévre, Tajana Begović

\begin{abstract}
The surface properties of Polytetrafluoroethylene (PTFE) depend on the $\mathrm{pH}$ and the ionic strength of the electrolyte solution. The point of zero charge $\left(\mathrm{pH}_{\mathrm{pzc}}\right)$ and the isoelectric point $\left(\mathrm{pH}_{\mathrm{iep}}\right)$ of PTFE were found to be 2.9 and 3.2 at $25{ }^{\circ} \mathrm{C}$, respectively. The electrophoretic mobility at $\mathrm{pH}>\mathrm{pH}_{\mathrm{iep}}$ indicates that the PTFE particles are negatively charged in the neutral $\mathrm{pH}$ region. In absence of surface functional groups, this observation can be explained by the distribution of $\mathrm{OH}^{-}$and $\mathrm{H}^{+}$ions between the PTFE interface and the remaining solution. A thermodynamic model of ion distribution and the temperature dependency of the electroneutrality points which enables evaluation of the thermodynamic parameters is proposed. The enthalpies of interfacial reactions were indirectly determined by measuring the temperature dependency of the electroneutrality points by potentiometric mass titration and streaming current measurements. It was found that the exchange of the $\mathrm{H}^{+}$and $\mathrm{OH}^{-}$ions between the interfacial region and bulk of the solution is an endothermic reaction. The specific enthalpy of dilution of PTFE dispersions was found to be $\mathrm{pH}$ dependent, with the lowest value at $\mathrm{pH} \approx 3$, i.e. in the zero surface charge region.
\end{abstract}

\section{KEYWORDS}

Polytetrafluoroethylene (PTFE), ion distribution, electrical interfacial layer, enthalpy of interfacial reactions, point of zero charge, isoelectric point 


\section{INTRODUCTION}

Hydrophobic materials, such as inert gases, hydrocarbon oils, ice, polytetrafluoroethylene (PTFE, Teflon ${ }^{\circledR}$ ) or diamond do not bear surface functional groups and therefore should neither chemically react with water molecules nor with ions from aqueous electrolyte solution. Due to their hydrophobicity water dipoles are repelled from the surfaces and orientation of water molecules becomes less random than in the bulk of the solution. The resulting ordering and the concomitant distribution of water molecules and ions in the vicinity of the surface cause the formation of an electrical interfacial layer (EIL) [1,2]. Due to their unexpected charging behavior, the interfacial properties of such inert hydrophobic materials in aqueous electrolyte solutions have been the subject of numerous experimental as well as theoretical investigations [3-7]. A number of experimental techniques, such as electrokinetic [4-9], surface tension [10] or bubble potential measurements [11,12], have been applied in order to evaluate surface properties and charge distribution at these inert material/aqueous solution interfaces. It was found for all hydrophobic materials that the electrophoretic mobility, and thus the net electrokinetic charge and even surface potentials are $\mathrm{pH}$ dependent. Furthermore the electroneutrality points of inert materials occur in the acidic region, around $\mathrm{pH} \approx 3$, which in turn means that below $\mathrm{pH} \approx 3$ the inert material/aqueous electrolyte solution interface is net positive, while above $\mathrm{pH} \approx 3$ the interface is net negative. The origin of the electrical charge of the inert material/aqueous electrolyte solution interface, and its $\mathrm{pH}$ dependency, have been the subject of numerous debates over the years and the issue is still not solved [1-4,10,13-17]. While several models of electrical charging of inert materials for ambient conditions were proposed [18], the purpose of this article is to apply a model to evaluate thermodynamic parameters for surface charging of inert materials. In this respect the enthalpy of surface reactions was directly determined by means of calorimetric experiments and indirectly by measuring the temperature dependency of some equilibrium properties. The indirect method for determination of reaction enthalpy includes the temperature dependency of some equilibrium properties. A suitable experimental quantity that provides the required information about surface equilibrium is the electroneutrality point. At the electroneutrality point, surface potential and surface charge density equal zero, so that the electrostatic contribution to the thermodynamic functions, i.e. Gibbs energy, enthalpy and entropy is absent.

In terms of surface reactions, the equilibrium state is represented through the thermodynamic equilibrium constants which are concealed in the values of the electroneutrality points i.e. 
isoelectric point (IEP) and point of zero charge (PZC). Determination of accurate electroneutrality points is relevant to the evaluation of thermodynamic parameters and the development of models for processes which take place within the interfacial layer.

The standard method for the determination of the IEP of solid colloidal particles is electrophoresis [19,20]. Electrophoresis is an electrokinetic phenomenon in which electrically charged dispersed particles move relative to a fluid under the influence of an externally applied uniform electric field. If the mobility of the particles equals zero, the system is at the electrophoretic isoelectric point. The IEP of the same solid material but with different macroscopic dimensions or shapes i.e. crystal plane, plate or pellets can be obtained by streaming potential (or streaming current) measurements [20,21]. Streaming potential and streaming current are electrokinetic phenomena caused by an aqueous electrolyte solution that is driven by a pressure gradient through a channel or porous plug with charged walls. The measured value of the streaming potential (current) difference is related to the zeta potential of the charged surface.

A standard method for the determination of the PZC of solid colloid particles is potentiometric acid-base titration [22]. The PZC of colloid particles can also be obtained from the results of such titrations of aqueous electrolyte dispersions for at least two (better three) ionic strengths. If a sample does not contain acidic or basic contaminations potentiometric acid-base titration would yield the absolute charge related to the surface reactions of protons and hydroxide ions. In the case of contaminated samples relative surface charges are obtained. The results are highly sensitive to the accuracy of $\mathrm{pH}$ measurement, exact volume addition and preparation of solutions with precisely known concentration. Another applicable method for determination of the PZC is potentiometric mass titration. It was developed as a suitable tool for determination of the PZC and the surface charge density of metal oxide colloidal particles at different ionic strengths [22,23], and has several advantages compared to the acidbase titration. First, the procedure is simple, second the comparison with the blank titration is avoided and third the salt content of the dispersion remains constant. In such a titration, known portions of a solid powder are added to an aqueous electrolyte solution, and the $\mathrm{pH}$ of the equilibrated dispersion is measured. The $\mathrm{pH}$ gradually changes and approaches a constant value, which (in the case of pure samples) equals the point of zero charge, $\mathrm{pH}_{\mathrm{pzc}}$. This makes determination of temperature dependency of $\mathrm{pH}_{\mathrm{pzc}}$ or $\mathrm{pH}_{\mathrm{eln}}$ simple [24]. Accordingly, this procedure allows the evaluation of the chemical (standard) part of thermodynamic quantities i.e. reaction enthalpy, entropy and Gibbs energy. Several reports provide the enthalpy 
evaluated from the temperature dependency of PZC of metal oxides [25-31] (Figure 1). Unlike inert materials, at metal oxide surfaces electrically charged and chemically reactive surface groups exist. The respective surface chemical reactions on these surfaces are commonly described by surface complexation models [32].

It was found that the PZC of metal oxides decreases as temperature increases. Slight changes in the temperature do not cause significant shifts in the $\mathrm{pH}_{\mathrm{pzc}}$ value. For measurable differences in $\mathrm{pH}_{\mathrm{pzc}}$, temperature shifts of at least $5 \mathrm{~K}$ are recommended. At temperatures below $200^{\circ} \mathrm{C}$ a negative slope in $\mathrm{pH}_{\mathrm{pzc}}(T)$ is observed indicating that the process of surface protonation is exothermic.

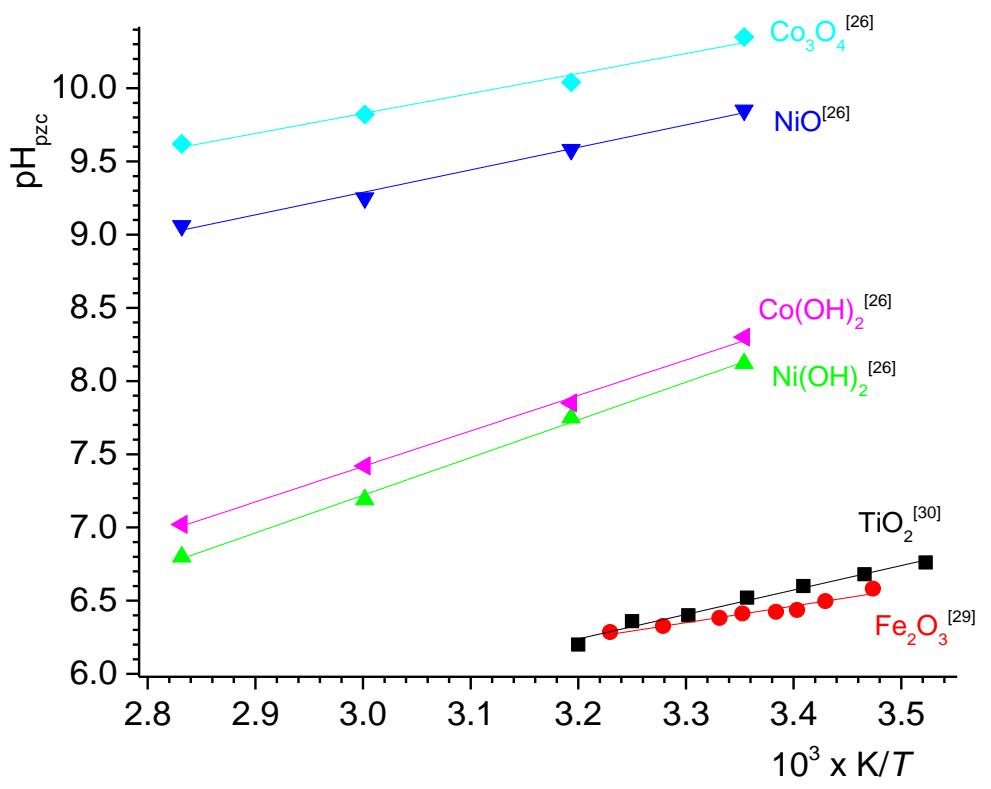

Figure 1. Temperature dependency of $\mathrm{pH}_{\mathrm{pzc}}$ for various metal oxides as reported by Tewari (1976) [26], Preočanin (2002) [29] and Kallay (2003) [30].

Compared to this indirect approach, a direct method for evaluation of thermodynamic quantities is calorimetric titration. In order to examine the distribution of hydrogen and hydroxide ions in a calorimetric experiment the colloidal suspension can be titrated with acid or base. During such an experiment several surface reactions, as well as neutralization in the bulk of the solution, occur. It is not easy to separate the extents of the different reactions in a calorimetric vessel and to calculate the respective contributions to the measured heat, i.e. enthalpy change. If the calorimetry experiments are performed outside the electroneutrality region, the electrostatic contribution needs to be included [33]. Therefore, any calorimetric experiment should be carefully planned taking into account all possible reactions and processes. 
The intention of this article is to investigate the reactions and processes within the interfacial layer of PTFE/aqueous electrolyte solutions with focus on temperature dependency. We propose a thermodynamic model for describing the accumulation of the potential determining ions $\left(\mathrm{H}^{+}\right.$and $\left.\mathrm{OH}^{-}\right)$near the surface of the inert particles. The processes accompanying the dilution of a concentrated dispersion of chemically inert PTFE particles are additionally discussed. Thermodynamic parameters of the above mentioned processes are obtained indirectly and directly, from the temperature dependency of equilibrium parameters and from calorimetry, respectively. Electroneutrality points are reported in the temperature range from $10{ }^{\circ} \mathrm{C}$ to $50{ }^{\circ} \mathrm{C}$ by measuring the streaming current near flat PTFE planes as well as the $\mathrm{pH}$ values of concentrated dispersion of purified PTFE colloidal particles. Additionally, calorimetric experiments involving the dilution of concentrated PTFE dispersions enable the evaluation of the electroneutrality point and yield insight into the energetic changes in the PTFE dispersion. The results are compared with the values obtained for surface reactions which take place at metal oxide colloidal particles.

\section{THEORY: THERMODYNAMIC MODEL}

The ionic equilibrium within the EIL can be interpreted by the surface complexation model or by distribution/accumulation of potential determining ions between the interfacial layer and the bulk of the solution. At a metal oxide surface in aqueous environment interfacial functional groups exist and react with potential determining ions [32]. The surface charging of inert surfaces based on the accumulation of hydrogen (hydronium) and hydroxide ions at the interface thus considers the distribution of $\mathrm{H}^{+}$and $\mathrm{OH}^{-}$ions between the bulk of the solution (aq) and the interfacial region (三)

$$
\begin{array}{ccc}
\mathrm{H}^{+}(\mathrm{aq}) f & \equiv \mathrm{H}^{+} & K^{\mathrm{O}}\left(\mathrm{H}^{+}\right)=\frac{\exp \left(\Psi_{0} F / R T\right) \cdot x\left(\equiv \mathrm{H}^{+}\right)}{a_{c}\left(\mathrm{H}^{+}\right)} ; \Delta_{\mathrm{r}} H^{\mathrm{o}}\left(\mathrm{H}^{+}\right) \\
\mathrm{OH}^{-}(\mathrm{aq}) f \equiv \mathrm{OH}^{-} & K^{\mathrm{o}}\left(\mathrm{OH}^{-}\right)=\frac{\exp \left(-\Psi_{0} F / R T\right) \cdot x\left(\equiv \mathrm{OH}^{-}\right)}{a_{c}\left(\mathrm{OH}^{-}\right)} ; \Delta_{\mathrm{r}} H^{\mathrm{o}}\left(\mathrm{OH}^{-}\right)
\end{array}
$$

where $K^{\circ}\left(\mathrm{H}^{+}\right)$and $K^{\circ}\left(\mathrm{OH}^{-}\right)$denote the respective thermodynamic equilibrium constants. The relative activities of interfacial $\mathrm{H}^{+}$and $\mathrm{OH}^{-}$are expressed as amount (mole) fractions $x\left(\equiv \mathrm{H}^{+}\right)$ and $x\left(\equiv \mathrm{OH}^{-}\right) . \Psi_{0}$ denotes interfacial potential, i.e. the electrostatic potential affecting the state of interfacial $\mathrm{H}^{+}$and $\mathrm{OH}^{-}$[34]. The relative activity of bulk $\mathrm{H}^{+}$and $\mathrm{OH}^{-}\left(a_{c}\left(\equiv \mathrm{H}^{+}\right)\right.$and $\left.a_{c}\left(\equiv \mathrm{OH}^{-}\right)\right)$are expressed in terms of molar concentrations In this special case, hydronium and hydroxide ions result from the self-ionization of bulk water 


$$
\mathrm{H}_{2} \mathrm{O}(\mathrm{l}) f \quad \mathrm{H}^{+}(\mathrm{aq})+\mathrm{OH}^{-}(\mathrm{aq}) \quad K_{\mathrm{w}, \mathrm{bulk}}^{\mathrm{o}}=\frac{a\left(\mathrm{H}^{+}\right) \cdot a\left(\mathrm{OH}^{-}\right)}{a\left(\mathrm{H}_{2} \mathrm{O}\right)} \approx a\left(\mathrm{H}^{+}\right) \cdot a\left(\mathrm{OH}^{-}\right) ; \Delta_{\mathrm{w}, \text { bulk }} H^{\mathrm{o}}
$$

as well as from self-ionization of interfacial water molecules

$$
\equiv \mathrm{H}_{2} \mathrm{O} f \equiv \mathrm{H}^{+}+\equiv \mathrm{OH}^{-} \quad K_{\mathrm{w}, \mathrm{bulk}}^{\mathrm{o}}=\frac{a\left(\equiv \mathrm{H}^{+}\right) \cdot a\left(\equiv \mathrm{OH}^{-}\right)}{a\left(\equiv \mathrm{H}_{2} \mathrm{O}\right)} \approx a\left(\equiv \mathrm{H}^{+}\right) \cdot a\left(\equiv \mathrm{OH}^{-}\right) ;
$$

For the electrolyte solutions we are interested in the relative activity of water in the liquid phase and in the interfacial region is approximately 1 . Due to different physical and chemical properties of water at inert hydrophobic surfaces the values of the thermodynamic equilibrium constants of bulk and interfacial water differ [35]. According to the literature [34], the value of the thermodynamic equilibrium constant based on concentration for ionization of bulk water at $25^{\circ} \mathrm{C}$ is $K_{\mathrm{w}, \mathrm{bulk}, \mathrm{c}}^{\mathrm{O}}=1.006 \times 10^{-14}$. The value based on amount fraction of $\mathrm{H}^{+}$and $\mathrm{OH}^{-}$ ions calculated using molar mass and density of water is equal to $K_{\mathrm{w}, \mathrm{bulk}, x}^{\mathrm{O}}=3.26 \times 10^{-18}$. The value of the interfacial thermodynamic equilibrium constant based on amount fraction of $\mathrm{H}^{+}$ and $\mathrm{OH}^{-}$ions, obtained from experimental surface potential and electrokinetic potential data of the gas/water interface is $K_{\mathrm{w}, \text { int }, x}^{\mathrm{o}}=8.7 \times 10^{-6}$. Consequently, the degree of interfacial water molecule dissociation is about $10^{6}$ times higher than in the bulk of the solution [21].

Within the model the surface potential $\Psi_{0}$ affecting the state of interfacial $\mathrm{H}^{+}$and $\mathrm{OH}^{-}$ions can be related to bulk $\mathrm{pH}$, the ratio of amount fractions of interfacial by $\mathrm{H}^{+}$and $\mathrm{OH}^{-}$ions, and thermodynamic equilibrium constants of distribution reactions.

Electroneutrality of the interfacial layer surface is achieved if the interfacial amounts of $\mathrm{H}^{+}$ and $\mathrm{OH}^{-}$are equal, $x\left(\equiv \mathrm{H}^{+}\right)=x\left(\equiv \mathrm{OH}^{-}\right)$, i.e. $\Psi_{0}=0$. In the case of symmetrical counterion association, or even lack of counterion association, the electroneutrality point coincides with the IEP (i.e. $\zeta=0$ ) and PZC (i.e. $\sigma_{0}=0$ ), so that $\mathrm{pH}_{\mathrm{eln}}=\mathrm{pH}_{\mathrm{iep}}=\mathrm{pH}_{\mathrm{pzc}}$ [32]. The electroneutrality point $\mathrm{pH}_{\mathrm{eln}}$ is determined by the corresponding equilibrium constant(s),

$$
\mathrm{pH}_{\mathrm{eln}}=\frac{1}{2} \lg \frac{K^{\mathrm{O}}\left(\mathrm{H}^{+}\right)}{K^{\mathrm{O}}\left(\mathrm{OH}^{-}\right) \cdot K_{\mathrm{w}, \text { bulk,c }}^{\circ}}
$$

The usually reported IEP and PZC, are standard parameters that characterize dispersed solid particles in aqueous electrolyte solutions, and affect the electrical surface properties such as adsorption of ions and colloidal stability. While the values of the thermodynamic equilibrium constants of surface reactions cannot be directly determined the electroneutrality points are relatively easily obtained. For example, at surface electroneutrality the mobility of particles in 
an applied electrical field is equal to zero, the surface concentrations of positively and negatively charged ions within the interfacial region are equal.

By changing conditions in the colloidal dispersion, such as $\mathrm{pH}$, ionic strength, concentration of colloid particles, temperature, changes within the interfacial layer occur. Variations in the distribution of potential determining ions (Eqs. 1 and 2), dissociation of water molecules (Eqs. 3 and 4) or reorientation of water molecules near the surface [36] changes the equilibrium state, and affect the electrical charge densities of the colloidal particles and the total interaction energy. Energy changes of the accompanying surface reactions are characterized by enthalpy changes, while the standard Gibbs energies of surface reactions are directly related to the corresponding intrinsic equilibrium constants:

$$
-R T \ln K^{\mathrm{o}}=\Delta_{\mathrm{r}} G^{\mathrm{o}}=\Delta_{\mathrm{r}} H^{\mathrm{o}}-T \Delta_{\mathrm{r}} S^{\mathrm{o}}
$$

Combining equations (5) and (6) yields the electroneutrality point of inert material/aqueous electrolyte solutions:

$$
\mathrm{pH}_{\mathrm{eln}}=-\frac{\Delta_{\mathrm{r}} H^{\mathrm{o}}\left(\mathrm{H}^{+}\right)-\Delta_{\mathrm{r}} H^{\mathrm{o}}\left(\mathrm{OH}^{-}\right)-\Delta_{\mathrm{w}, \text { bulk }} H^{\mathrm{o}}}{2 R T \ln 10}+\frac{\Delta_{\mathrm{r}} S^{\mathrm{o}}\left(\mathrm{H}^{+}\right)-\Delta_{\mathrm{r}} S^{\mathrm{o}}\left(\mathrm{OH}^{-}\right)-\Delta_{\mathrm{w}, \text { bulk }} S^{\mathrm{o}}}{2 R \ln 10}
$$

Consequently, the chemical (standard) part of surface reactions enthalpies can be evaluated from the temperature dependency of the electroneutrality point:

$$
\frac{\mathrm{dpH}}{\mathrm{d}(1 / T)}=-\frac{\Delta_{\mathrm{r}} H^{\mathrm{o}}\left(\mathrm{H}^{+}\right)-\Delta_{\mathrm{r}} H^{\mathrm{o}}\left(\mathrm{OH}^{-}\right)-\Delta_{\mathrm{w}} H^{\mathrm{o}}}{2 R \ln 10}
$$

The enthalpy change $\Delta_{\mathrm{r}} H^{\mathrm{o}}\left(\mathrm{H}^{+}\right)-\Delta_{\mathrm{r}} H^{\mathrm{o}}\left(\mathrm{OH}^{-}\right)-\Delta_{\mathrm{w}} H^{\mathrm{o}}$ is related to the reaction

$$
2 \mathrm{H}^{+}(\mathrm{aq})+\equiv \mathrm{OH}^{-} f \equiv \mathrm{H}^{+}+\mathrm{H}_{2} \mathrm{O}(\mathrm{l})
$$

which involves exchange of $\mathrm{H}^{+}$and $\mathrm{OH}^{\top}$ between interfacial layer and bulk solution (Figure 2a) and ionization of a water molecule (Eq. 3) in solution (step 2 on Figure 2b):

Ionization of a water molecule and formation of $\mathrm{H}^{+}$and $\mathrm{OH}^{-}$in aqueous bulk solution is exothermic $\left(\Delta_{\mathrm{w}, \mathrm{bulk}} H^{\mathrm{o}} \approx 56 \mathrm{~kJ} \mathrm{~mol}^{-1}\right.$ [37]). The determination of the enthalpy concerning the exchange of $\mathrm{H}^{+}$and $\mathrm{OH}^{-}$ions requires subtraction of $\Delta_{\mathrm{w}, \mathrm{bulk}} H^{\mathrm{o}}$ :

$$
\mathrm{H}^{+}(\mathrm{aq})+\equiv \mathrm{OH}^{-} f \equiv \mathrm{H}^{+}+\mathrm{OH}^{-}(\mathrm{aq}) \quad \Delta_{\mathrm{r}} H^{\mathrm{o}}(\text { overall })=\Delta_{\mathrm{r}} H^{\mathrm{o}}\left(\mathrm{H}^{+}\right)-\Delta_{\mathrm{r}} H^{\mathrm{o}}\left(\mathrm{OH}^{-}\right)
$$




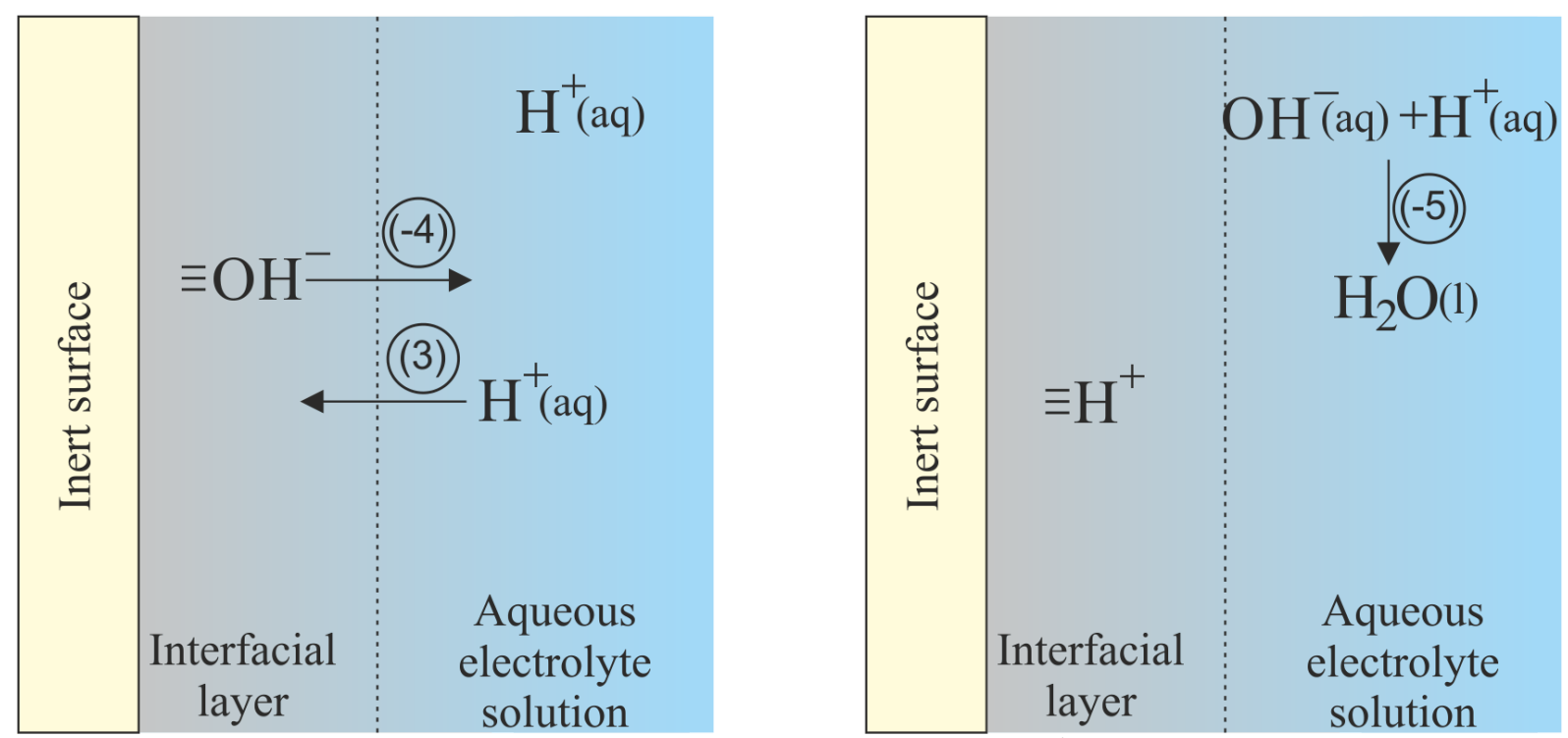

Figure 2. The overall reaction (Eq. 9) involves exchange of $\mathrm{H}^{+}$(Eq. 1) and $\mathrm{OH}^{-}$(Eq. 2) ions between interfacial layer and bulk of the solution and dissociation (Eq. 3) of water molecule in the bulk of the aqueous electrolyte solution.

The temperature dependency of $\mathrm{pH}_{\mathrm{eln}}$ provides a difference in standard reaction enthalpies, but not individual values. Outside the electroneutrality region the surface is electrically charged. The thermodynamic property $\Delta_{\mathrm{r}} X$ (where $X$ denotes $G, H$ or $S$ ) must then be expressed as the sum of the standard $\Delta_{\mathrm{r}} X^{0}$ and the electrostatic $\Delta_{\mathrm{r}} X_{\mathrm{el}}$ parts

$$
\Delta_{\mathrm{r}} X=\Delta_{\mathrm{r}} X^{\mathrm{o}}+\Delta_{\mathrm{r}} X_{\mathrm{el}}
$$

These electrostatic contributions are connected to the surface potential ( $\left.\Psi_{0}\right)$ by

$$
\Delta_{\mathrm{r}} G_{\mathrm{el}}=\Delta z F \Psi_{0}
$$

where $\Delta z$ is the change in the charge number due to interfacial reactions; for reactions (1) $\Delta z$ $=+1$, and for reaction (2) $\Delta z=-1$. The electrostatic contribution is related to the temperature dependency of the surface potential as

$$
\Delta_{\mathrm{r}} H_{\mathrm{el}}=\Delta z F \Psi_{0}-\Delta z F T\left(\frac{\partial \Psi_{0}}{\partial T}\right)
$$

While the standard part of the reaction enthalpy can be obtained from the temperature dependence of the electroneutrality point, the determination of the electrical part the temperature dependency requires the inner surface potential.

The reactions involving counter - ion association within the ion distribution approach for cations can be expressed as:

$$
\mathrm{C}^{+}(\mathrm{aq}) f \equiv \mathrm{C}^{+} \quad K^{\mathrm{o}}\left(\mathrm{C}^{+}\right)=\frac{\exp \left(\Psi_{\beta} F / R T\right) \cdot x\left(\equiv \mathrm{C}^{+}\right)}{a_{c}\left(\mathrm{C}^{+}\right)} ; \Delta_{\mathrm{r}} H^{\mathrm{o}}\left(\mathrm{C}^{+}\right)
$$


and for anions as:

$$
\mathrm{A}^{-}(\mathrm{aq}) f \equiv \mathrm{A}^{-} \quad K^{\mathrm{O}}\left(\mathrm{A}^{-}\right)=\frac{\exp \left(-\Psi_{\beta} F / R T\right) \cdot x\left(\equiv \mathrm{A}^{-}\right)}{a_{c}\left(\mathrm{~A}^{-}\right)} ; \Delta_{\mathrm{r}} H^{\mathrm{o}}\left(\mathrm{A}^{-}\right)
$$

Here $K^{\mathrm{O}}\left(\mathrm{C}^{+}\right)$and $K^{\mathrm{O}}\left(\mathrm{A}^{-}\right)$denote the corresponding thermodynamic equilibrium constants. The relative activities of the interfacial $\mathrm{C}^{+}$and $\mathrm{A}^{-}$are expressed as amount (mole) fractions $x\left(\equiv \mathrm{C}^{+}\right)$ and $x\left(\equiv \mathrm{A}^{-}\right)$and $\Psi_{\beta}$ is the interfacial potential at the so-called $\beta$-plane, that affects the state of interfacial $\mathrm{C}^{+}$and $\mathrm{A}^{-}$. The relative bulk activities of $\mathrm{C}^{+}$and $\mathrm{A}^{-}$are expressed as their molar concentrations.

If the affinity of cations towards negatively charged interfacial entities is higher than that of the accompanying anions towards positively charged ones (preferential association of cations, $\left.K^{\mathrm{o}}\left(\mathrm{C}^{+}\right)>K^{\mathrm{o}}\left(\mathrm{A}^{-}\right)\right)$, the IEP is shifted from the electroneutrality point $\mathrm{pH}_{\text {eln }}$ to higher $\mathrm{pH}$ values, while the $\mathrm{PZC}$ is shifted to lower $\mathrm{pH}$ values, i.e. $\mathrm{pH}_{\mathrm{iep}}>\mathrm{pH}_{\mathrm{eln}}>\mathrm{pH}_{\mathrm{pzc}}$ [38]. For the preferential association of anions $\left(K_{\mathrm{A}}^{\mathrm{o}}>K_{\mathrm{C}}^{\mathrm{o}}\right)$ the shifts are in the opposite directions: $\mathrm{pH}_{\mathrm{pzp}}>$ $\mathrm{pH}_{\mathrm{eln}}>\mathrm{pH}_{\mathrm{iep}}$. PZC shifts are expected to be smaller than those in IEP [39]. A difference between IEP and PZC $\left(\mathrm{pH}_{\mathrm{iep}} \neq \mathrm{pH}_{\mathrm{pzc}}\right)$ indicates unequal association of anions and cations. The temperature dependency of the IEP and PZC in those cases contains finite but small electrostatic contribution.

As mentioned earlier, the heat measured in calorimetric experiments (during addition of acid or base) includes contributions from all surface and bulk reactions. Therefore, we designed a calorimetric experiment which only targeted the distribution of potential determining ions i.e. we measured the heat exchange due to dilution of concentrated colloidal PTFE dispersions. We performed an isothermal calorimetric experiment in which a small amount of concentrated dispersion is added to the aqueous electrolyte solution of the same $\mathrm{pH}$ and ionic strength. The dilution of the colloidal dispersion of particles $\mathrm{P}$ from mass concentration $\gamma_{1}$ to mass concentration $\gamma_{2}$ can be expressed by the following equation:

$$
\mathrm{P}\left(\gamma_{1}\right) \rightarrow \mathrm{P}\left(\gamma_{2}\right) \quad \Delta H_{\text {dil }}
$$

Here $\Delta H_{\text {dil }}$ is the enthalpy change for the dilution process, i.e. an extensive physical quantity which depends on the size of the system. The extent of the dilution reaction is not easy to calculate for interfacial reactions. In order to obtain an intensive physical quality, the specific enthalpy change $\Delta h_{\text {dil }}$, the measured enthalpy change is divided by the mass of added PTFE

$$
\Delta h_{\mathrm{dil}}=\frac{\Delta H_{\mathrm{dil}}}{m}=\frac{\Delta H_{\mathrm{dil}}}{\gamma V}
$$


$\mathrm{pH}<\mathrm{pH}_{\text {eln }} \quad \mathrm{pH}=\mathrm{pH}_{\text {eln }} \quad \mathrm{pH}>\mathrm{pH}_{\text {eln }}$
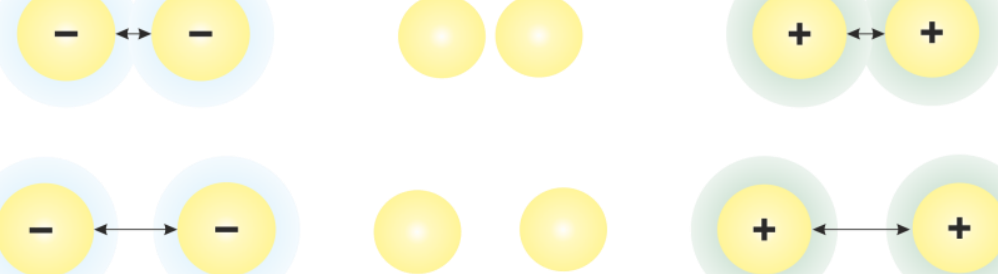

Figure 3. The process of dilution (Eq. 16) in the calorimetric experiment, at constant $\mathrm{pH}$ and ionic strength, involves increasing the distance between two PTFE particles and consequently a reduction in electrostatic interactions of electrically charged particles (for $\mathrm{pH} \neq \mathrm{pH} \mathrm{eln}_{\text {n }}$ )

During dilution several processes may take place. The state within the interfacial region stays the same because $\mathrm{pH}$ and ionic strange do not change. Due to dilution the particles are moved apart from each other and overall interaction decreases. Additionally, the overlap of the electrostatic interfacial layer reduces and solvation increases. The electrostatic interactions depend on the electrical properties of the particles (potential and charge densities) which are related to the $\mathrm{pH}$ and the ionic strength of the aqueous electrolyte solution, Figure 3. For $\mathrm{pH}=$ $\mathrm{pH}_{\mathrm{eln}}$ all electrical properties $\left(\Psi_{0}, \sigma_{0}\right.$ and $\zeta$ ) and electrostatic interactions vanish. For $\mathrm{pH} \neq$ $\mathrm{pH}_{\mathrm{eln}}$ repulsive electrostatic interactions occur, and the heat of dilution depends on $\mathrm{pH}$ and ionic strength.

\section{MATERISLAS AND METHODES}

Materials: All solutions and dispersions were prepared using MiliQ water. All measurements were made in the presence of argon gas to avoid carbon dioxide dissolving in water. The glass electrode was calibrated by using standard buffer solutions (Fluka) in the temperature range $10{ }^{\circ} \mathrm{C}-50{ }^{\circ} \mathrm{C}$.

Two samples were used, PTFE particles and flat PTFE sheets. PTFE particles were obtained from Polysciences Inc. (Microdispers-200), with a specified mean particle size of 200-300 $\mathrm{nm}$. The specific surface area of the PTFE particles determined using the BET (BrunauerEmmett-Teller) method (Micromeritics, Gemini using liquid nitrogen) was $s=7.2 \mathrm{~m}^{2} / \mathrm{g}$. The PTFE particles were used for the temperature dependency of the PZC charge and in the calorimetry experiments. 
Due to the hydrophobicity of PTFE particles a high mass dispersion of PTFE particles was prepared by dispersing dry PTFE in a small amount of $96 \%$ ethanol. Then water and $\mathrm{NaCl}$ were added and the dispersion was left until all detectable ethanol had evaporated.

The second PTFE sample was a flat conventional PTFE sheet from Dalau Ltd. The sample was cut into rectangular shape $(20 \mathrm{~mm} \times 10 \mathrm{~mm})$ for streaming current measurements with the adjustable gap cell of the Surpass Apparatus Gen 1 type A (Anton Paar).

The temperature dependency of the PZC and IEP of PTFE materials was evaluated by the following experimental methods.

\subsection{Potentiometric mass titration of PTFE}

To determine the minimum amount of PTFE that buffers the $\mathrm{pH}$ of a dispersion, initially neutral, the $\mathrm{pH}$ was followed while adding PTFE powder to a stirred $\mathrm{KCl} 10^{-2} \mathrm{~mol} \mathrm{dm}^{-3}$ solution. Due to the hydrophobicity of the PTFE, this protocol did not allow to incorporate the whole amount of the solid. Yet at mass concentrations above nominal $100 \mathrm{~g} / \mathrm{dm}^{3}$ the dispersion reached the PZC condition. The PZC of PTFE dispersion is in the same $\mathrm{pH}$ region $\left(\mathrm{pH}_{\mathrm{pzc}} \approx 3.5\right)$ as the $\mathrm{pH}_{\mathrm{iep}}[18]$. The $\mathrm{pH}$ value of uncontaminated dispersions of high mass concentration, $\mathrm{pH}_{\infty}$, corresponds to the $\mathrm{pH}_{\mathrm{pzc}}[23]$.

\subsection{Temperature dependency of the point of zero charge}

The $\mathrm{pH}$ values of concentrated PTFE dispersions $\left(\mathrm{pH}_{\infty}=\mathrm{pH}_{\mathrm{pzc}}\right)$ were measured between 10 ${ }^{\circ} \mathrm{C}$ and $50{ }^{\circ} \mathrm{C}$. The initial composition of the investigated PTFE dispersions is presented in Table 1. The mass concentrations of the PTFE dispersions were $100 \mathrm{~g} / \mathrm{dm}^{3}$ (sample A), 50 $\mathrm{g} / \mathrm{dm}^{3}$ (sample $\mathbf{B}$ ) and $2 \mathrm{~g} / \mathrm{dm}^{3}$ (samples $\mathbf{C}$ and $\mathbf{D}$ ). The mass concentrations of samples $\mathbf{A}$ and B were sufficient to reach $\mathrm{pH}_{\infty}$. In the diluted PTFE dispersion of $2 \mathrm{~g} / \mathrm{dm}^{3}$ (samples C) the $\mathrm{pH}$ was 5.75, so that the particles were negatively charged. In the second diluted PTFE dispersion (sample D) the $\mathrm{pH}$ value was adjusted to the PZC by addition of hydrochloric acid. Sample $\mathbf{E}$ represents an initial solution of $20 \mathrm{~cm}^{3} \mathrm{KCl} 1 \times 10^{-2} \mathrm{~mol} \mathrm{dm}{ }^{-3}$ to which a mass of $5 \mathrm{~g}$ of PTFE was added, leading to a concentration of $\approx 250 \mathrm{~g} / \mathrm{dm}^{3}$, but due to the hydrophobicity of PTFE not all PTFE particles incorporated in the suspension. Sample F contained only hydrochloric acid $c(\mathrm{HCl})=1 \times 10^{-3} \mathrm{~mol} \mathrm{dm}{ }^{-3}$, without PTFE particles. 
The systems were kept under an argon atmosphere and were thermostated $\left( \pm 0.1^{\circ} \mathrm{C}\right)$. The $\mathrm{pH}$ was measured by a combined (glass $-\mathrm{Ag} / \mathrm{AgCl} / \mathrm{KCl}$ ) electrode.

Table 1. The composition of the investigated PTFE dispersion samples at $25^{\circ} \mathrm{C}$.

\begin{tabular}{ccccc}
\hline Sample & $\gamma / \mathrm{g} \mathrm{dm}^{-3}$ & $c(\mathrm{NaCl}) / \mathrm{mol} \mathrm{dm}^{-3}$ & $c(\mathrm{HCl}) / \mathrm{mol} \mathrm{dm}^{-3}$ & Condition \\
\hline $\mathrm{A}$ & 100 & $10^{-3}$ & 0 & $\mathrm{pH}_{\infty}=\mathrm{pH}_{\mathrm{pzc}}$ \\
$\mathrm{B}$ & 50 & $10^{-3}$ & 0 & $\mathrm{pH}_{\infty}=\mathrm{pH}_{\mathrm{pzc}}$ \\
$\mathrm{C}$ & 2 & $10^{-3}$ & 0 & $\mathrm{pH}>\mathrm{pH}_{\mathrm{pzc}}$ \\
$\mathrm{D}$ & 1 & 0 & $6 \times 10^{-4}$ & $\mathrm{pH}_{\mathrm{pzc}}$ \\
$\mathrm{E}$ & $\approx 250$ & $10^{-2}(\mathrm{KCl})$ & $1 \times 10^{-2}$ & $\mathrm{pH}_{\infty}=\mathrm{pH}_{\mathrm{pzc}}$ \\
$\mathrm{F}$ & 0 & 0 & $1 \times 10^{-3}$ & without particles \\
\hline
\end{tabular}

\subsection{Temperature dependency of isoelectric point}

Streaming current measurements were performed using the SurPass apparatus of Anton Paar. Aqueous solutions were prepared with $\mathrm{NaCl}\left(I_{\mathrm{c}}=1 \times 10^{-3} \mathrm{~mol} \mathrm{dm}^{-3}\right)$, while $\mathrm{NaOH}$ and $\mathrm{HCl}$ were used for $\mathrm{pH}$ control. The $\mathrm{pH}$ was measured by a combined (glass - $\mathrm{Ag} / \mathrm{AgCl} / \mathrm{KCl}$ ) electrode. The electrode was calibrated using standard buffer solutions (Fluka Analytical) in the temperature range $10{ }^{\circ} \mathrm{C}-50{ }^{\circ} \mathrm{C}$. The aqueous solution was thermostated in a large vessel and temperature was monitored throughout the experiments in this vessel and within the streaming potential cell. Before gluing the two PTFE plates to the holders with double side tape they were pretreated with the aqueous solution that contained $1 \times 10^{-3} \mathrm{~mol} \mathrm{dm}^{-3} \mathrm{NaCl}$ and $\mathrm{NaOH}$ as proposed by R. Šstar and coworkers [40]. The gap height was manually adjusted to approximately $100 \mu \mathrm{m}$.

\subsection{Heat of dilution}

Microcalorimetric experiments were performed by means of an isothermal titration calorimeter (CSC 4200 ITC, Calorimetry Sciences Corporation) at $25.0{ }^{\circ} \mathrm{C}$. The calorimeter was calibrated electrically and chemically by means of the standard reaction of protonation of tris(hydroxymethyl)aminomethane (THAM) with $\mathrm{HCl}(\mathrm{aq})$. Calorimetric data were processed using Titration Bindworks and OriginPro 7.5. The calorimeter reaction cell was filled with sodium chloride and hydrochloric acid solution of the appropriate $\mathrm{pH}$ values $\left(V=1.3 \mathrm{~cm}^{3}, I_{c}\right.$ $\left.=1 \times 10^{-2} \mathrm{~mol} \mathrm{dm}^{-3}\right)$. The enthalpy changes were recorded upon stepwise, automatic additions (5 min intervals) of PTFE particles $\left(15 \mu \mathrm{L}\right.$ of $\left.\gamma=1 \mathrm{~g} \mathrm{dm}^{-3}\right)$ dispersed in the aqueous solution 
of the $\mathrm{HCl} / \mathrm{NaCl}$ solution present in reaction cell, from a $250 \mu \mathrm{L}$ Hamilton syringe. All measurements were repeated three times.

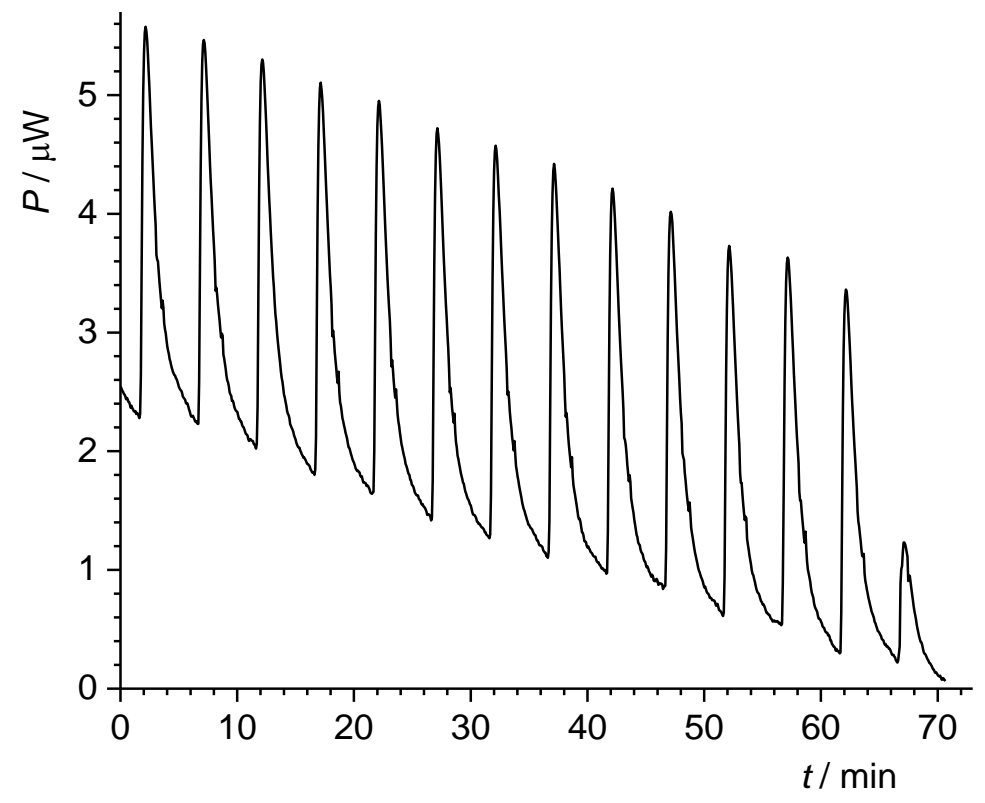

Figure 4. Microcalorimetric titration of sodium chloride and hydrochloric acid solution $(V=$ $1.3 \mathrm{~mL}$ ) of the $\mathrm{pH}=2.95$ with $15 \mu \mathrm{L}$ PTFE dispersion $\left(\mathrm{pH} 2.95 ; \gamma=1 \mathrm{~g} \mathrm{dm}^{-3}\right)$ at $\theta=25^{\circ} \mathrm{C}$.

As an example, a thermogram obtained in a titration of an aqueous $\mathrm{HCl} / \mathrm{NaCl}$ solution $(\mathrm{pH}=$ 2.95) with PTFE dispersion $\left(\gamma=1 \mathrm{~g} \mathrm{dm}^{-3}, \mathrm{pH}=2.95\right)$ at $25{ }^{\circ} \mathrm{C}$ is shown in Figure 4. The stepwise addition of PTFE dispersion resulted in exothermic enthalpy changes. Successive enthalpy changes are obtained by integration of the calorimetric peeks. The standard specific enthalpy for the dilution of the PTFE dispersion was calculated by a least squares linear regression analysis.

\section{RESULTS AND DISCUSION}

\subsection{Mass titration}

Potentiometric mass titrations of PTFE by continuous addition of solid particles to an aqueous potassium chloride solution were continued until reaching a constant $\mathrm{pH}$ value $\left(\mathrm{pH}_{\infty} \rightarrow\right.$ $\left.\mathrm{pH}_{\mathrm{pzc}}\right)$. Results are presented on Figure 5. The PZC of PTFE according to the results at $25^{\circ} \mathrm{C}$ is 3.2. A constant $\mathrm{pH}$ value was reached at mass concentration higher than $130 \mathrm{~g} / \mathrm{dm}^{3}$. 


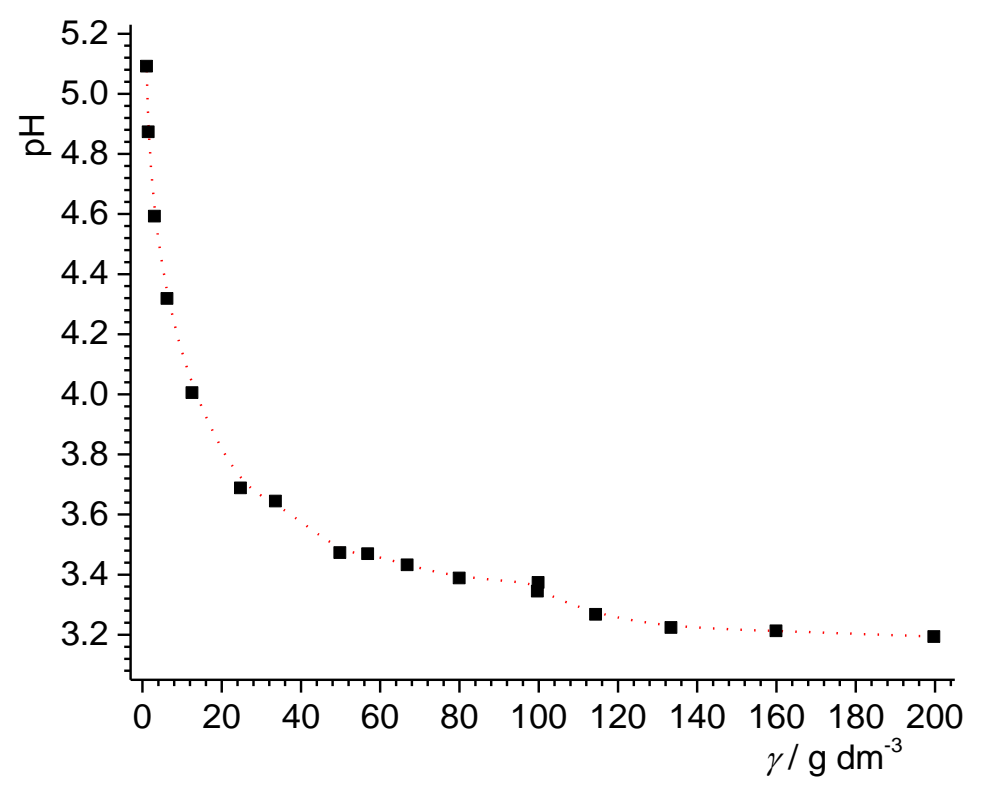

Figure 5. Mass titration of $1 \times 10^{-2} \mathrm{~mol} \mathrm{dm}{ }^{-3}$ potassium chloride aqueous solution with PTFE particles at $25^{\circ} \mathrm{C}$.

The temperature dependency of the PZC was determined by measuring the $\mathrm{pH}$ of the PTFE dispersions of high mass concentrations (A: $100 \mathrm{~g} / \mathrm{dm}^{3}$ and B: $50 \mathrm{~g} / \mathrm{dm}^{3}, \mathbf{E}: 250 \mathrm{~g} / \mathrm{dm}^{3}$ ) and also of the diluted PTFE dispersion $\left(\mathbf{D}: 1 \mathrm{~g} / \mathrm{dm}^{3}\right.$ ) in which $\mathrm{pH}$ was adjusted to the $\mathrm{pH}_{\mathrm{pzc}}$ by $\mathrm{HCl}(\mathrm{aq})$. Additionally, the temperature dependencies of the $\mathrm{pH}$ in a pure PTFE dispersion $(\mathbf{C}$ : $1 \mathrm{~g} / \mathrm{dm}^{3}$ ) and a blank solution of hydrochloric acid (F) without PTFE particles were measured. For all measured systems the $\mathrm{pH}$ value is increasing with increasing temperature. More precisely, a linear dependency of $\mathrm{pH}$ on $1 / T$ was found, Figure 6 . From the slopes of the $\mathrm{pH}_{\mathrm{pzc}}(1 / T)$ lines for suspensions $\mathbf{A}$ and $\mathrm{B}$, eq. 8, the difference in standard enthalpies of distribution of hydronium and hydroxide ions between the PTFE interface and bulk aqueous sodium solution was obtained. In the PZC region the electrostatic contributions can be neglected. For the concentrated PTFE dispersions, $\Delta_{\mathrm{r}} H^{\circ}\left(\mathrm{H}^{+}\right)-\Delta_{\mathrm{r}} H^{\circ}\left(\mathrm{OH}^{-}\right)$was found to be $(76 \pm 2) \mathrm{kJ} \mathrm{mol}^{-1}$, Table 2. The insignificant temperature dependence of $\mathrm{pH}$-values of PTFE in a dilute hydrochloric acid solution (blank sample $\mathbf{F}$ ) indicates that measurement accuracy is about $3 \mathrm{~kJ} \mathrm{~mol}^{-1}$.

A slightly lower value $\left(63 \mathrm{~kJ} \mathrm{~mol}^{-1}\right)$ was obtained for PTFE particles in diluted dispersions but with $\mathrm{pH}$ adjusted to the PZC. Overall, the results indicate that reaction (eq. 10), i.e. exchange of the $\mathrm{H}^{+}$and $\mathrm{OH}^{-}$ions between the interfacial region and bulk of the solution is an extremely endothermic reaction. In other worlds, it is necessary to invest about $72 \mathrm{~kJ}$ energy for binding of $1 \mathrm{~mol} \mathrm{H}^{+}$ions to the PTFE surface compared to binding of $1 \mathrm{~mol} \mathrm{OH}^{-}$ions. 


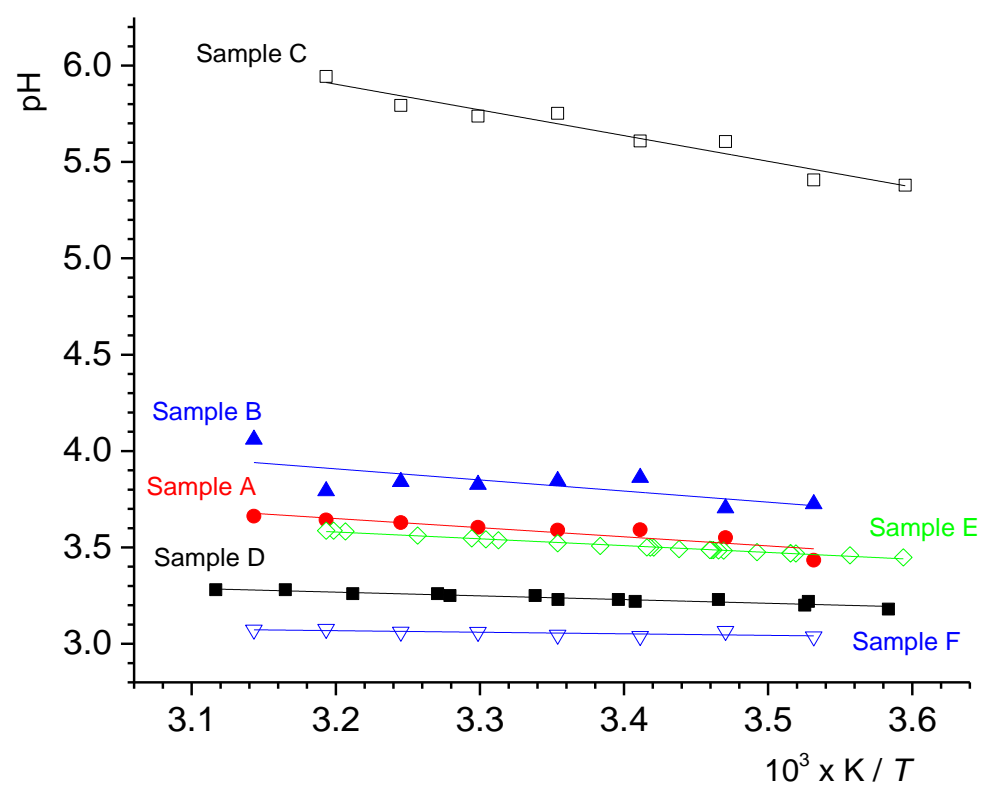

Figure 6. Temperature dependency of pH for: $\left(\bullet\right.$, sample A) $100 \mathrm{~g} / \mathrm{dm}^{3}$ PTFE dispersion in 1 mmol dm ${ }^{-3} \mathrm{NaCl}(\mathrm{aq})$; ( $\boldsymbol{\Delta}$, sample B) $50 \mathrm{~g} / \mathrm{dm}^{3}$ PTFE dispersion in $1 \mathrm{mmol} \mathrm{dm}{ }^{-3} \mathrm{NaCl}(\mathrm{aq})$; (ロ, sample C) $1 \mathrm{~g} / \mathrm{dm}^{3}$ PTFE dispersion in $1 \mathrm{mmol} \mathrm{dm}{ }^{-3} \mathrm{NaCl}(\mathrm{aq})$; (匹, sample D) $1 \mathrm{~g} / \mathrm{dm}^{3}$ in $6 \times 10^{-4} \mathrm{~mol} \mathrm{dm}{ }^{-3} \mathrm{HCl}(\mathrm{aq})$; $\left(\diamond\right.$, sample E) $250 \mathrm{~g} / \mathrm{dm}^{3}$ PTFE dispersion in $10 \mathrm{mmol} \mathrm{\textrm {dm } ^ { - 3 }}$ $\mathrm{KCl}(\mathrm{aq})$ and $(\nabla$, sample $\mathbf{F}) 1 \mathrm{mmol} \mathrm{dm}{ }^{-3} \mathrm{HCl}(\mathrm{aq})$.

For the dilute PTFE dispersion, with $\mathrm{pH}>\mathrm{pH}_{\mathrm{pzc}}$ (sample $\mathbf{C}$ ) the $\mathrm{pH}$ change includes electrostatic contributions to the enthalpy of ion distribution. The slope of the $\mathrm{pH}(1 / T)$ function yields an electrostatic contribution of around $33 \mathrm{~kJ} / \mathrm{mol}$, similar to what was previously reported for metal oxides, where the electrostatic contribution for two step protonation of negatively charged hematite surface sites $\left(\equiv \mathrm{FeO}^{-}+2 \mathrm{H}^{+}(\mathrm{aq}) \rightarrow \equiv \mathrm{FeOH}_{2}^{+}\right)$was found to be $42 \mathrm{~kJ} \mathrm{~mol}^{-1}$ [35]. Two step protonation is also the process of the accumulation of hydronium ions within the interfacial region of PTFE.

From the intercepts of the obtained $\mathrm{pH}(1 / T)$ lines the standard values of differences in reaction entropy of hydronium and hydroxide ion distribution between the PTFE interface and the bulk of the aqueous sodium chloride solution were evaluated, Table 2. Assuming that enthalpy and entropy are constant within the examined temperature range the standard values of the reaction Gibbs energy were calculated and are included in Table 2. 
Table 2. Thermodynamic parameters for hydronium and hydroxide ion distribution between the PTFE interface and bulk of the aqueous sodium chloride solution described by eq. 10 .

\begin{tabular}{ccccccc}
\hline Sample & $\gamma / \mathrm{g} \mathrm{dm}^{-3}$ & $\mathrm{pH}_{25} /$ & slope $/ \mathrm{K}$ & $\frac{\Delta_{\mathrm{r}} H^{\circ}(\text { overall })}{\mathrm{kJ} \mathrm{mol}^{-1}}$ & $\frac{\Delta_{\mathrm{r}} S^{\mathrm{o}}(\text { overall })}{\mathrm{J} \mathrm{K}^{-1} \mathrm{~mol}^{-1}}$ & $\frac{\Delta_{\mathrm{r}} G^{\circ}(\text { overall })}{\mathrm{kJ} \mathrm{mol}^{-1}}$ \\
\hline $\mathrm{A}$ & 100 & 3.6 & -474 & 74 & 117 & 39 \\
$\mathrm{~B}$ & 50 & 3.8 & -576 & 78 & 139 & 36 \\
$\mathrm{C}$ & 1 & 5.7 & -1333 & $107^{*}$ & $309^{*}$ & $15^{*}$ \\
$\mathrm{D}$ & 1 & 3.2 & -193 & 63 & 68 & 43 \\
E & $\approx 250$ & 3.2 & -353 & 69 & 100 & 40 \\
F & 0 & 3.0 & -81 & $\mathrm{NA}$ & $\mathrm{NA}$ & $\mathrm{NA}$ \\
PTFE plate & 0 & 2.9 & - & - & - & - \\
\hline
\end{tabular}

* Electrostatic contributions are included

There is a significant difference in the temperature dependency of PZC between PTFE particles (Figure 6) and metal oxide particles (Figure 1). For the metal oxides the $\mathrm{pH}_{\mathrm{pzc}}$ decreases with increase in temperature. Blesa [27] applied the surface dissociation model to the available thermodynamic data and concluded that entering of hydronium ions into the inner layer and reacting with negative surface groups is an energetically favorable reaction with an enthalpy contribution ranging from -20 to $-40 \mathrm{~kJ} \mathrm{~mol}^{-1}$ and an entropy contribution between 20 and $100 \mathrm{~J} \mathrm{~K}^{-1} \mathrm{~mol}^{-1}$.

\subsection{Electrokinetic measurements}

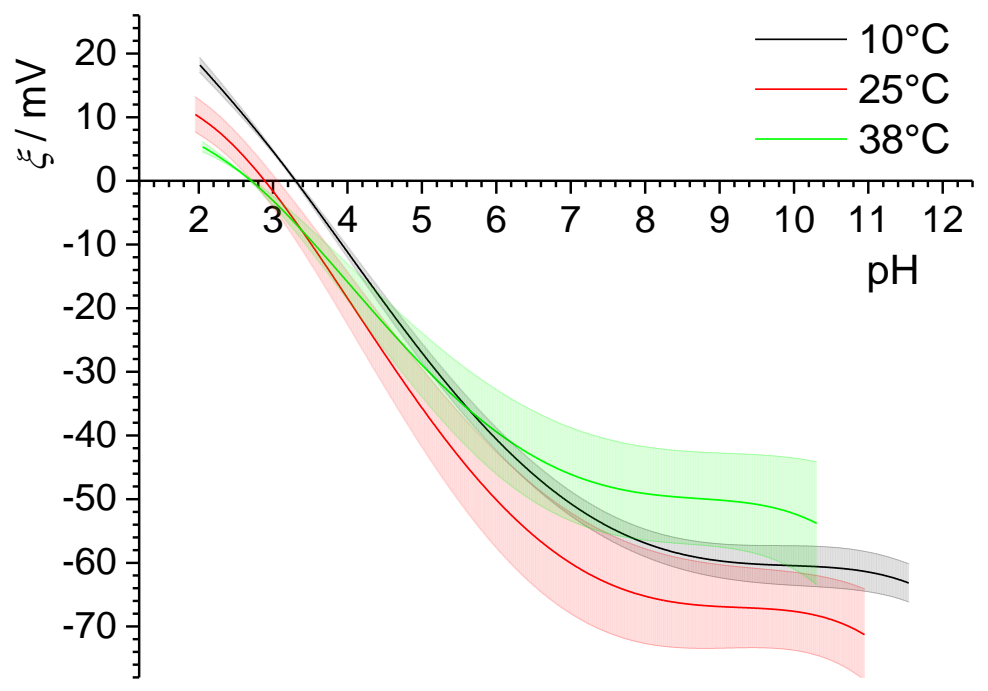


Figure 7. Electrokinetic potential of PTFE plate in $1 \mathrm{mmol} \mathrm{dm}^{-3}$ sodium chloride aqueous solution at different temperatures. Average function (bold curves) with SD bars (transparent areas) are plotted.

Electrokinetic $\zeta$-potentials of PTFE plates in $1 \mathrm{mmol} \mathrm{dm}^{-3} \mathrm{NaCl}(\mathrm{aq})$ at three different temperatures $\left(10{ }^{\circ} \mathrm{C}, 25^{\circ} \mathrm{C}\right.$ and $\left.38{ }^{\circ} \mathrm{C}\right)$ were obtained from measured streaming current. Figure 7. shows the average functions (with standard deviation bars) of at least three measurements at the same temperature. The value of $\zeta$-potential depends on $\mathrm{pH}$, crossing the zero $(\zeta=0)$ at the IEP. The average IEP of PTFE decreases as temperature increases, which is opposite to the measured PZC temperature dependency for concentrated PTFE suspensions. Due to overlap, the uncertainty of the IEP determination at $25^{\circ} \mathrm{C}$ and $10^{\circ} \mathrm{C}$ does not allow to claim a significant temperature dependence of the IEP. However, the small magnitude in the variation of the IEP values is in agreement with PZC temperature dependence. The IEP of the PTFE plates used in these experiments at $25^{\circ} \mathrm{C}$ is found to be $2.9 \pm 0.4$ (Table 2.).

Additional measurements of electrophoretic mobility and conductance for PTFE suspensions as a function of temperature (see SI) actually suggest a decrease of the IEP with decreasing temperature, which agrees with the mass titration results for the same system. Interestingly, differences between particles and flat samples have been observed for similar systems [41].

\subsection{Calorimetry}

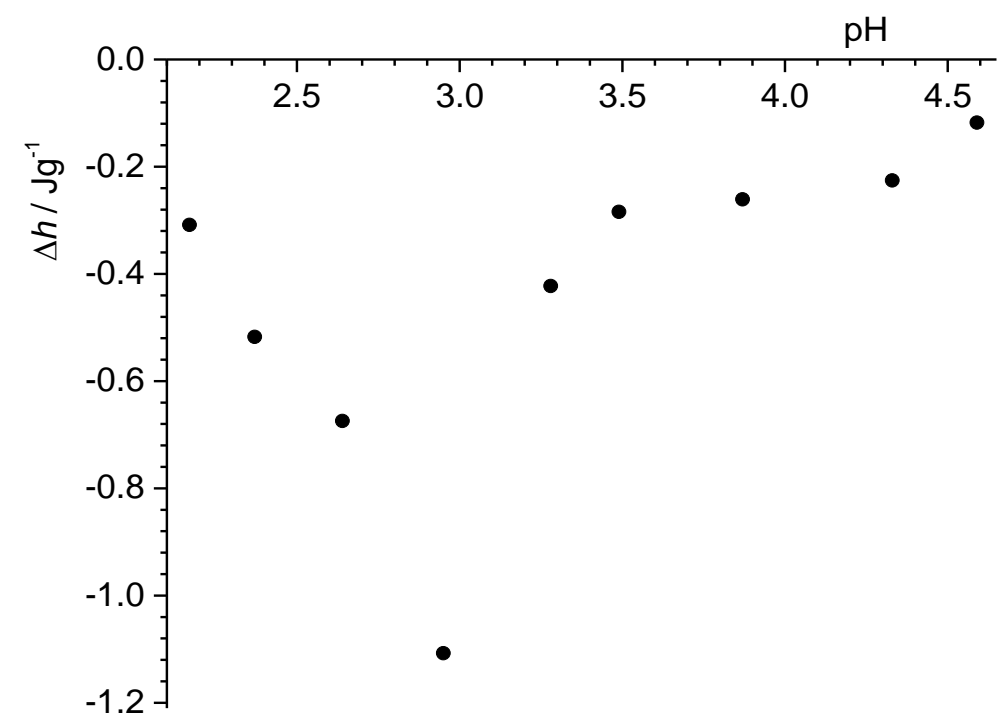


Figure 8. Specific enthalpy of dilution of PTFE dispersion; $\left(\gamma=1 \mathrm{~g} \mathrm{dm}^{-3}\right)$ with sodium chloride/hydrochloric acid aqueous solution of different $\mathrm{pH}$-values at $t=25^{\circ} \mathrm{C}$.

Integration of the calorimetric peaks in the dilution series yields the successive enthalpy change. The specific enthalpies for the dilution of the PTFE dispersion as calculated by a least squares linear regression analysis of calorimetric titration data are shown in Figure 8. The specific enthalpy of dilution of PTFE dispersions was found to be $\mathrm{pH}$ dependent, with the lowest $\Delta h$ value at $\mathrm{pH} \approx 3$, close to the measured PZC and IEP. During dilution of PTFE dispersion several processes take place. Our calorimetric experiments were designed in a way that $\mathrm{pH}$ and ionic strength do not change throughout. After addition of $10 \mu \mathrm{L}$ of PTFE suspension to the calorimetric vessel the mass concentration of PTFE decreases by a factor of 100. Due to dilution the PTFE particles are moved apart and the overall interactions between them diminishes. Since PTFE is highly hydrophobic, particles tend to aggregate. Dilution of electrically uncharged particles is energetically more unfavored (due to hydrophobicity) than for electrically charged particles (at $\left.\mathrm{pH} \neq \mathrm{pH}_{\mathrm{eln}}\right)$. In the electroneutrality region $\left(\mathrm{pH} \approx \mathrm{pH}_{\mathrm{eln}}\right)$, the minimum of specific heat of dilution was observed, which can be explained by absence of repulsive electrostatic interactions between PTFE particles. By contrast, at $\mathrm{pH} \neq \mathrm{pH} \mathrm{eln}_{\mathrm{ln}}$ particles are positively or negatively charged, and repulsive electrostatic interactions are noticeable. During the dilution of a charged PTFE suspension the interactions between particles decrease and less exothermic effects were measured. As a consequence of dilution the hydrophobic PTFE surface tends to reduce the contact with aqueous solution and a redistribution of potential-determining ions $\left(\mathrm{H}^{+}\right.$and $\left.\mathrm{OH}^{-}\right)$takes place. The distribution of these ions affects the state within the interfacial region.

\section{CONCLUSIONS}

For PTFE surfaces the positions of $\mathrm{pH}_{\mathrm{iep}}$ and $\mathrm{pH}_{\mathrm{pzc}}$ were determined to be 2.9 and 3.2 at 25 ${ }^{\circ} \mathrm{C}$, respectively. The electroneutrality point was additionally confirmed by a calorimetric experiment as a minimum of specific enthalpy change $\Delta h_{\text {dil }}$. These values indicate that hydroxide ions can more easily accumulate in the EIL than hydronium ions. The observation is in accordance with other experiments made on inert/aqueous solution interfaces $[12,18,42,43]$. A positive value of reaction Gibbs free energy for the exchange reaction of $\mathrm{H}^{+}$ and $\mathrm{OH}^{-}$ions between the interfacial layer and the bulk of the solution (Eq. 10) is in correspondence with the above conclusion showing that the reverse process (hydroxide ions 
entering inert material layer and pushing hydronium ions in bulk of solution) is spontaneous. From the calculated reaction enthalpy and entropy, we can conclude that the reverse process is enthalpy driven.

Acknowledgments: The authors are grateful to the Laboratory for Precipitation Processes, Ruđer Bošković Institute (Zagreb, Croatia) for BET measurements and the Department of Textile Chemistry Technology and Ecology, Faculty of Textile Technology (University of Zagreb) where streaming current measurements were done.

Funding: This work has been supported by Croatian Science Foundation under the project (IP-2014-09-6972). 


\section{Refrences:}

[1] B. Winter, M. Faubel, R. Vácha, P. Jungwirth, Behavior of hydroxide at the water/vapor interface, Chem. Phys. Lett. 474 (2009) 241-247.

https://doi.org/10.1016/j.cplett.2009.04.053.

[2] A. Gray-Weale, Comment on 'Behaviour of Hydroxide at the water/vapor interface, Chem. Phys. Lett. 241 (2009) 22-24. https://doi.org/10.1016/j.cplett.2009.09.008.

[3] J.K. Beattie, A.M. Djerdjev, W.G. Gregory, The surface of neat water is basic, Faraday Discuss. 141 (2009) 9-30. https://doi.org/10.1039/B816684F.

[4] B. Winter, M. Faubel, R. Vácha, P. Jungwirth, Reply to comments on Frontiers Article "Behavior of hydroxide at the water/vapor interface," Chem. Phys. Lett. 481 (2009) 19-21. https://doi.org/10.1016/j.cplett.2009.09.010.

[5] S.H. Cho, J.Y. Kim, J.H. Chun, J.D. Kim, Ultrasonic formation of nanobubbles and their zeta-potentials in aqueous electrolyte and surfactant solutions, Colloids Surfaces A Physicochem. Eng. Asp. 269 (2005) 28-34. https://doi.org/10.1016/j.colsurfa.2005.06.063.

[6] R. Zimmermann, S. Dukhin, C. Werner, Electrokinetic measurements reveal interracial charge at polymer films caused by simple electrolyte ions, J. Phys. Chem. B. 105 (2001) 8544-8549. https://doi.org/10.1021/jp004051u.

[7] L. Kong, J.K. Beattie, R.J. Hunter, Electroacoustic study of concentrated oil-in-water emulsions, J. Colloid Interface Sci. 238 (2001) 70-79. https://doi.org/10.1006/jcis.2001.7464.

[8] S. Usui, T.W. Healy, Zeta potential of insoluble monolayer of long-chain alcohol at the air - Aqueous solution interface, J. Colloid Interface Sci. 240 (2001) 127-132. https://doi.org/10.1006/jcis.2001.7661.

[9] M. Takahashi, $\zeta$ Potential of Microbubbles in Aqueous Solutions: Electrical Properties of the Gas-Water Interface, J. Phys. Chem. B. 109 (2005) 21858-21864. https://doi.org/10.1021/jp0445270.

[10] J.K. Beattie, A.M. Djerdjev, The pristine oil/water interface: Surfactant-free hydroxidecharged emulsions, Angew. Chemie - Int. Ed. 43 (2004) 3568-3571. https://doi.org/10.1002/anie.200453916.

[11] M. Manciu, E. Ruckenstein, Ions near the air/water interface: I. Compatibility of zeta potential and surface tension experiments, Colloids Surfaces A Physicochem. Eng. Asp. 400 (2012) 27-35. https://doi.org/10.1016/j.colsurfa.2012.02.038.

[12] T. Preočanin, F. Šupljika, M. Lovrak, J. Barun, N. Kallay, Bubbling potential as a measure of the charge of gas bubbles in aqueous environment, Colloids Surfaces A Physicochem. Eng. Asp. 443 (2014) 129. https://doi.org/10.1016/j.colsurfa.2013.11.002.

[13] B.C. Garrett, Ions at the Air/Water Interface, Science 303 (2004) 1146-1147. https://doi.org/10.1126/science.1089801.

[14] K.N. Kudin, R. Car, Why are water-hydrophobic interfaces charged?, J. Am. Chem. 
Soc. 130 (2008) 3915-3919. https://doi.org/10.1021/ja077205t.

[15] R. Vácha, V. Buch, A. Milet, J.P. Devlin, P. Jungwirth, Autoionization at the surface of neat water: is the top layer $\mathrm{pH}$ neutral, basic, or acidic?, Phys. Chem. Chem. Phys. 9 (2007) 4736. https://doi.org/10.1039/b704491g.

[16] P. Creux, J. Lachaise, A. Graciaa, J.K. Beattie, A.M. Djerdjev, Strong specific hydroxide ion binding at the pristine oil/water and air/water interfaces, J. Phys. Chem. B. 113 (2009) 14146-14150. https://doi.org/10.1021/jp906978v.

[17] D. Ehre, E. Lavert, M. Lahav, I. Lubomirsky, Water freezes differently on positively and negatively charged surfaces of pyroelectric materials, Science 327 (2010) 672-675. https://doi.org/10.1126/science.1178085.

[18] T. Preočanin, A. Selmani, P. Lindqvist-Reis, F. Heberling, N. Kallay, J. Lützenkirchen, Surface charge at Teflon/aqueous solution of potassium chloride interfaces, Colloids Surfaces A Physicochem. Eng. Asp. 412 (2012) 120. https://doi.org/10.1016/j.colsurfa.2012.07.025.

[19] C. Yang, T. Dabros, D. Li, J. Czarnecki, J.H. Masliyah, Measurement of the zeta potential of gas bubbles in aqueous solutions by microelectrophoresis method, $\mathrm{J}$. Colloid Interface Sci. 243 (2001) 128-135. https://doi.org/10.1006/jcis.2001.7842.

[20] R.J. Hunter, Zeta Potential in Colloid Science: Principles and Applications, Academic Press Inc., London, 1981. https://doi.org/10.1016/C2013-0-07389-6.

[21] G. Werner, H. Körber, R. Zimmermann, S. Dukhin, H.J. Jacobasch, Extended electrokinetic characterization of flat solid surfaces, J. Colloid Interface Sci. 208 (1998) 329-346. https://doi.org/10.1006/jcis.1998.5787.

[22] J. Lützenkirchen, T. Preočanin, D. Kovačević, V. Tomišić, L. Lövgren, N. Kallay, Potentiometric Titrations as a Tool for Surface Charge Determination, Croat. Chem. Acta. 85 (2012) 391-417. https://doi.org/10.5562/cca2062.

[23] J.N. Noh, J.A. Schwarz, Estimation of the Point of Zero Charge of Simple Oxides by Mass Titration, J. Colloid Interface Sci. 130 (1989) 157-164. https://doi.org/10.1016/S0032-5910(99)00011-X.

[24] M. Barale, C. Mansour, F. Carrette, E.M. Pavageau, H. Catalette, G. Lefèvre, M. Fedoroff, G. Cote, Characterization of the surface charge of oxide particles of PWR primary water circuits from 5 to $320^{\circ} \mathrm{C}$, J. Nucl. Mater. 381 (2008) 302-308. https://doi.org/10.1016/j.jnucmat.2008.09.003.

[25] N. Kallay, T. Preočanin, Application of „Mass Titration“ to Determination of Surface Charge of Metal Oxides, Croat. Chem. Acta. 71 (1998) 1117-1125.

[26] P.H. Tewari, A.B. Campbell, Temperature dependence of point of zero charge of cobalt and nickel oxides and hydroxides, J. Colloid Interface Sci. 55 (1976) 531-539. https://doi.org/10.1016/0021-9797(76)90063-1.

[27] M.A. Blesa, A.J.G. Maroto, A.E. Regazzoni, Surface acidity of metal oxides immersed in water: A critical analysis of thermodynamic data, J. Colloid Interface Sci. 140 (1990) 287-290. https://doi.org/10.1016/0021-9797(90)90343-M.

[28] L.G.J. Fokkink, A. de Keizer, J. Lyklema, Temperature dependance of the electrical double layer on oxides: Rutile and hematite, J. Colloid Interface Sci. 127 (1989) 116- 
131. https://doi.org/10.1016/0021-9797(89)90012-X.

[29] T. Preočanin, S. Krehula, N. Kallay, Enthalpy of surface reactions: Temperature dependency of $\mathrm{pH}$ of acidic or basic concentrated hematite suspension, Appl. Surf. Sci. 196 (2002) 392-400. https://doi.org/10.1016/S0169-4332(02)00077-6.

[30] N. Kallay, T. Madić, K. Kučej, T. Preočanin, Enthalpy of interfacial reactions at TiO2 aqueous interface, Colloids Surfaces A Physicochem. Eng. Asp. 230 (2003) 3. https://doi.org/10.1016/j.colsurfa.2003.09.008.

[31] M. Kosmulski, Standard enthalpies of ion adsorption onto oxides from aqueous solutions and mixed solvents, Colloids Surfaces A Physicochem. Eng. Asp. 83 (1994) 237-243. https://doi.org/10.1016/0927-7757(93)02658-2.

[32] J. Lützenkirchen, Surface Complexation Modelling, 1st ed., Elsevier Ltd, London, 2006.

[33] N. Kallay, S. Žalac, Enthalpy of Interfacial Charging of Metal Oxide / Water systems, Croat. Chem. Acta. 67 (1994) 467.

[34] N. Kallay, T. Preočanin, A. Selmani, D. Kovačević, J. Lützenkirchen, H. Nakahara, O. Shibata, Thermodynamic model of charging the gas/water interface, J. Phys. Chem. C. 119 (2015) 997. https://doi.org/10.1021/jp507477u.

[35] N. Kallay, T. Preočanin, S. Žalac, H. Lewandowski, H.D. Narres, Electrostatic contribution to the enthalpy of charging at hematite/electrolyte interface, J. Colloid Interface Sci. 211 (1999) 401-407. https://doi.org/10.1006/jcis.1998.6003.

[36] S. Strazdaite, J. Versluis, H.J. Bakker, Water orientation at hydrophobic interfaces, J. Chem. Phys. 143 (2015). https://doi.org/10.1063/1.4929905.

[37] W.B. Holzapfel, Effect of pressure and temperature on the conductivity and ionic dissociation of water up to $100 \mathrm{kbar}$ and $1000^{\circ} \mathrm{C}$, J. Chem. Phys. 50 (1969) 4424-4428. https://doi.org/10.1063/1.1670914.

[38] N. Kallay, T. Preočanin, T. Ivšić, Determination of surface potentials from the electrode potentials of a single-crystal electrode, J. Colloid Interface Sci. 309 (2007) 21. https://doi.org/10.1016/j.jcis.2006.10.075.

[39] N. Kallay, T. Preočanin, D. Kovačević, J. Lützenkirchen, E. Chibowski, Electrostatic Potentials at Solid/Liquid Interfaces, Croat. Chem. Acta. 83 (2010) 357.

[40] R. Šoster, K. Stana-Kleinschek, M. Brumen, V. Ribitsch, Measurements of Zeta Potential of Poly(Tetrafluoroethylene) Foils, Mater. Sci. Forum. 480-481 (2005) 89. https://doi.org/10.4028/www.scientific.net/MSF.480-481.89.

[41] A. Selmani, J. Lutzenkirchen, N. Kallay, T. Preočanin, Surface and zeta potentials of silver halide single crystals: $\mathrm{pH}$-dependence in comparison to particle systems, J. Phys. Condens. Matter. 244104 (2014) 26. doi:10.1088/0953-8984/26/24/244104.

[42] J. Lützenkirchen, T. Preočanin, N. Kallay, A macroscopic water structure based model for describing charging phenomena at inert hydrophobic surfaces in aqueous electrolyte solutions, Phys. Chem. Chem. Phys. 10 (2008) 4946. https://doi.org/10.1039/b807395c.

[43] N. Kallay, F. Šupljika, T. Preočanin, Charging of water at inert and hydrophobic surfaces. Effect on interfacial properties of silver halides, Adsorption. 19 (2013) 211. https://doi.org/10.1007/s10450-012-9442-y. 